\title{
Eficiência na remoção de coliformes em águas cinza através da fitorremediação
}

\section{Efficiency in the removal of coliforms in gray waters through phytoremediation}

\author{
Verena S. Baracuhy ${ }^{1}$, Jórgerson P. G. Pereira ${ }^{2}$, Aline C. Ferreira ${ }^{3}$, Viviane F. Silva ${ }^{4},{\text { Nicola } S^{5}}^{5}$
}

Resumo-O semiárido é caracterizado pelas irregularidades pluviais e o tratamento de águas cinza para reuso na agricultura com tecnologia ecológica é uma forma de conviver com a seca nessas regiões. Nesse contexto, a pesquisa foi realizada no distrito de Ribeira no município de Cabaceiras/PB objetivando-se avaliar a eficiência da remoção dos coliformes totais e fecais do efluente tratado nas unidades de produção agrícola através da fitorremediação. Foram realizados dois tratamentos com e sem fitorremediação, a cultura utilizada foi o capim roxo. As águas cinza eram provenientes de uma lavanderia pública. Foram coletadas amostras mensais e analisadas os coliformes total e fecal (Escherichia coli). No tratamento sem fitorremediação, os coliformes totais variaram de $1,583 \times 10^{3}$ a 2,0224 x $10^{3}$ (UFC/100 mL) e quando o tratamento tinha o auxílio do capim roxo, ou seja, com fitorremediação os coliformes totais oscilaram de 1,354 x $10^{3}$ a 2,0224 x $10^{3}$ (UFC/100 mL). Ocorreu uma redução significativa de Escherichia coli no tratamento com fitorremediação. A utilização da fitorremediação no tratamento de águas cinza reduziu a presença de coliformes totais e fecal, sendo assim uma alternativa viável de tratamento, proporcionando um aumento da qualidade hídrica.

Palavras - chave: Escherichia coli, capim roxo, tratamento de água.

Abstract- The semiarid region is characterized by irregularities storm water and treatment of gray water for reuse in agriculture with ecological technology is a way to cope with the drought in these regions. In this context, the research was conducted in the district of the municipality of Ribeira Cabaceiras / PB aiming to evaluate the efficiency of removal of total and fecal coliforms in treated wastewater in agricultural production units through phytoremediation. Two treatments with and without phytoremediation were performed, the culture used was purple grass. The gray water was provided from the public laundry. Monthly samples were collected and analyzed total and fecal (Escherichia coli) coliforms. On the treatment without phytoremediation, total coliforms ranged from $1.583 \times 10^{3}$ to $2.0224 \times 10^{3}$ (UFC/100 ml) and when the treatment had purple grass, with phytoremediation then total coliforms ranged from $1.354 \times 10^{3}$ to $2,0224 \times 103$ (UFC/100 mL). There was a significant reduction of Escherichia coli in the treatment with phytoremediation. The use of phytoremediation in greywater treatment reduced the presence of total and fecal coliforms, making it a viable alternative treatment, providing an increased in water quality.

Keywords: Escherichia coli, purple grass, water treatment.

${ }^{1}$ Mestre em Recursos Naturais pela UFCG. Email: verena_schiel@yahoo.com

${ }^{2 ; 3}$ Professores da Universidade Federal de Campina Grande (UFCG). Email: alinecfx@ yahoo.com.br.

${ }^{4}$ Mestranda em Engenharia Agrícola na Universidade Federal de Campina Grande - UFCG. Email: flordeformosur@hotmail.com; linebrito@ homtail.com.

End.: Av. Aprígio Veloso, 882, Bodocongó, CEP: 58109-970, Campina Grande, PB. Tel.: (83) 2101-1491

${ }^{5}$ Professora da Universidade Federal Rural de Pernambuco (UFRPE). Email: nschiel@yahoo.com 


\section{INTRODUÇÃO}

O Brasil é conhecido por apresentar corpos d'água em abundância, porém muitas regiões sofrem problemas de escassez decorrentes da irregularidade das chuvas. O país possui $13,7 \%$ do total de água doce do mundo. Desse total, $70 \%$ estão localizadas na região norte, mais precisamente na bacia amazônica, os outros $30 \%$ estão distribuídos entre as demais regiões. O Nordeste é a região mais afetada pela escassez de água, tendo como complicador o clima que não favorece a precipitação de chuvas periódicas (HARTMANN, 2010).

A Política Nacional de Recursos Hídricos (Lei 9.433/97) cita que em situações de escassez, o uso prioritário dos recursos hídricos é o consumo humano e animal, e que a gestão dos recursos hídricos deve sempre proporcionar o uso múltiplo das águas. De acordo com a Agência Nacional de Águas - ANA (2011) a água, em função de suas qualidades e quantidades, propicia vários tipos de uso, isto é, múltiplos usos. O uso dos recursos hídricos por cada setor pode ser classificado como consuntivo e não consuntivo.

A criação de meios capazes de atenuar o gasto descontrolado da água é fundamental para a manutenção dos ecossistemas. No Brasil, desde a década de 80 vem se difundindo e valorizando o conceito de "construção sustentável" e a aplicação de seus conceitos. Mesmo assim, o desperdício é considerável. De acordo com Mancuso \& Santos (2003) a reutilização de resíduos consolida-se cada vez mais como um instrumento de grande importância para a preservação e conservação dos recursos naturais. Neste cenário, o reuso da água merece destaque por já possuir tecnologia consagrada para a sua implantação.

O semiárido, por exemplo, caracteriza-se como uma região que sofre com as frequentes secas prolongadas prejudicando a vida de milhares de pessoas, sendo necessária a criação de estratégias para mitigar tal fenômeno natural. A reutilização de água doméstica surge como uma alternativa no intuito de harmonizar a relação de demanda e oferta de água.

As águas cinzas são aquelas provenientes dos lavatórios, chuveiros, tanques e máquinas de lavar roupa e louça. Porém, quanto a este conceito, observa-se que ainda não há consenso internacional (FIORI et al., 2006). Segundo Gonçalves (2006) alguns autores não consideram como água cinza, mas sim como água negra a água residuária de cozinhas, devido às elevadas concentrações de matéria orgânica e de óleos e gorduras nelas presentes.

As mudanças de comportamento a respeito da gestão e tratamento com a água já estão se manifestando dentro da sociedade, apontando para o desenvolvimento sustentável (CAMPOS, 2003). Diante dessa necessidade, a Unidade de Produção Agrícola Controlada (UPAC), no distrito de Ribeira em Cabaceiras-PB, foi criada no intuito de buscar uma alternativa no tratamento da água.

De acordo moradores locais o distrito da Ribeira não dispõe de coleta e tratamento de esgoto doméstico.

As fossas sépticas vêm sendo utilizadas precariamente, com parâmetros operacionais muito abaixo dos aceitáveis pelos órgãos ambientais, representando mais um ônus para o distrito do que os benefícios que se pode esperar de um tratamento dessa natureza. Tal fato levou a administração municipal a buscar alternativas para que tais benefícios possam de fato atender a toda a comunidade e para que a cidade tenha o esgoto convenientemente tratado (FERREIRA, 2013).

A unidade de produção agrícola em Ribeira caracteriza-se como uma estação de tratamento, pois tem como base o processo de fitorremediação. Este processo é uma técnica de descontaminação, na qual se utilizam plantas para remover poluentes do ambiente ou transformá-los em formas menos perigosas para os seres vivos. O impacto ambiental e os custos de implementação são inferiores àqueles dos métodos físicos e químicos, além de ser uma técnica de fácil implementação (PILON-SMITS, 2005).

A fitorremediação utiliza sistemas vegetais para recuperar águas e solos contaminados por poluentes orgânicos ou inorgânicos. Esta área de estudo, embora não seja nova, tomou impulso nos últimos dez anos, quando se verificou que a zona radicular das plantas apresenta a capacidade de biotransformar moléculas orgânicas exógenas. A rizosfera, como é denominada esta zona, tem sido desde então estudada por sua importante função de utilizar moléculas poluentes como fonte de nutrientes para os diversos microrganismos que coabitam nesta região (DINARDI et al., 2003).

Nesse contexto, o presente trabalho foi realizado objetivando-se avaliar a eficiência da remoção dos coliformes totais e fecais do efluente tratado nas unidades de produção agrícola no semiárido Paraibano através da fitorremediação.

\section{MATERIAL E METODOS}

A pesquisa foi desenvolvida em uma Unidade de Produção Agrícola Controlada (UPAC) instalada no distrito de Ribeira (S $7^{\circ} 25^{\prime}$ e W $36^{\circ} 21^{\prime}$ ), no município de Cabaceiras que se situa no semiárido do cariri paraibano, com 2.500 habitantes e distam 183,8 km de João Pessoa, capital do Estado da Paraíba e $78 \mathrm{~km}$ de Campina Grande. Apresenta as seguintes coordenadas geográficas: $7^{\circ} 29^{\prime} 21^{\prime \prime} \mathrm{Sul}, 36^{\circ} 17^{\prime}$ $18^{\prime \prime}$ Oeste e uma altitude média de $400 \mathrm{~m}$ acima do nível do mar. Estas coordenadas estão inseridas na unidade geoambiental do Planalto da Borborema,

formada por maciços e outeiros altos, com altitude variando entre 650 a 1.000 metros (AESA, 2013; FERREIRA, 2013).

A Unidade de Produção Agrícola Controlada (UPAC) foi uma adaptação do modelo desenvolvido por Galbiati (2009) que se diferenciou na impermeabilização de cada unidade. Esta foi construída com oito subunidades ("tanques") de produção impermeáveis compostas de lonas plásticas e pneus velhos em uma área com aproximadamente $6 \mathrm{~m}^{2}$. O efluente proveniente da lavanderia é conduzido através da tubulação PVC de $100 \mathrm{~mm}$ até uma caixa de água de 500 litros para posterior distribuição às unidades experimentais. $\mathrm{O}$ reservatório foi posicionado de modo que todo efluente seja distribuído às subunidades por gravidade. A unidade de produção do presente estudo apresenta oito tanques, ou seja, oito subunidades (Figura 1) com dimensões de: $3,0 \times 2,0 \times 1,0 \mathrm{~m}$ o equivalente a aproximadamente $6 \mathrm{~m}^{2} \mathrm{de}$ área. As quatro primeiras subunidades correspondendo a T1a; T1b; T1c e T1d respectivamente não apresentam o cultivo de capim elefante enquanto que as demais subunidades $\mathrm{T} 2 \mathrm{a}$; $\mathrm{T} 2 \mathrm{~b}$; T2c e T2d cultivam quantidades semelhantes do capim com um espaçamento equivalente a $40 \mathrm{~cm}$ entre cada cultura.

Foram realizados amostragens mensais, num período de 4 meses, analisando os parâmetros microbiológicos de 
Coliformes totais e fecal (Escherichia coli) pelo método enzimático de substrato definido - Colilert. Para análise estatística o teste $\mathrm{z}$ binomial no qual o nível de significância
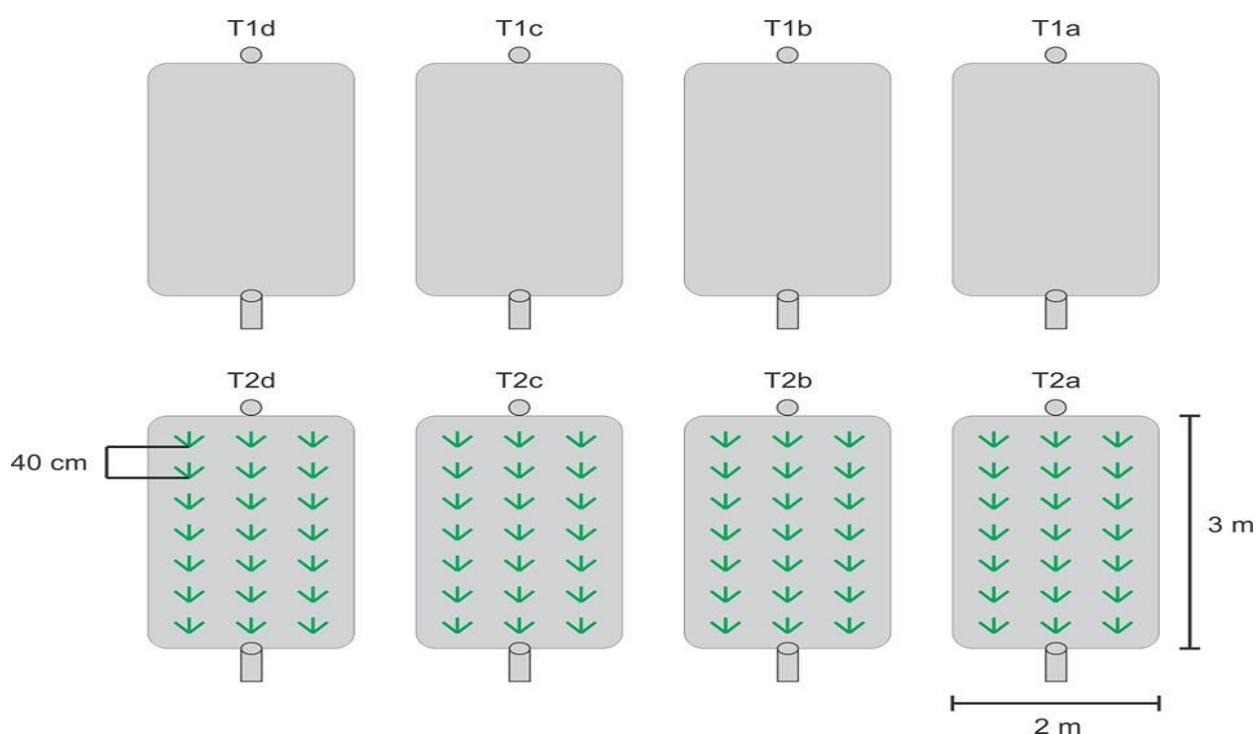

Figura 1. Representação do experimento em estudo

\section{RESULTADOS E DISCUSSÃO}

De acordo com a Tabela 1 os resultados para coliformes totais houve uma variação nos meses setembro e outubro.

No monitoramento o efluente bruto (água cinza sem tratamento) os valores de coliformes totais foram de $1,0112 \mathrm{x}$ $10^{3}$ a 2,0224 x $10^{3}$ UFC/100 mL. No tratamento sem fitorremediação, os coliformes totais variaram de $1,583 \times 10^{3}$ a $2,0224 \times 10^{3}$ (UFC/100 mL) e quando o tratamento tinha o auxilio do capim roxo, ou seja, com fitorremediação os coliformes totais oscilaram de 1,354 × $10^{3}$ a 2,0224 × $10^{3}$
UFC/100 mL. No tratamento com fitorremediação a remoção de coliformes totais foi de $18,19 \%$, enquanto que sem fitorremediação foi de 4,35\%, havendo assim uma diferença entre os tratamentos.

No tratamento com fitorremediação houve uma maior redução de coliformes totais (Figura 2), sendo assim a fitorremediação auxilia no tratamento de águas cinza. May \& Hespanhol (2008) estudando o tratamento de águas cinza claras para reuso não potável em edificações obtiveram uma média de concentração de coliformes totais nas águas cinza claras brutas de $1,4 \times 10^{4} \mathrm{UFC} / 100 \mathrm{~mL}$ estando este valor acima dos encontrados nesta pesquisa.

Tabela 1. Monitoramento da remoção dos coliformes totais nos tratamentos de águas cinza.

\begin{tabular}{lccc}
\hline Coliformes Totais & Efluente bruto & Tratamento sem fitorremediação & Tratamento com fitorremediação \\
\hline Setembro & $1,655 \times 10^{3}$ & $1,583 \times 10^{3}$ & $1,354 \times 10^{3}$ \\
Outubro & $1,755 \times 10^{3}$ & $1,635 \times 10^{3}$ & $1,532 \times 10^{3}$ \\
Novembro & $1,0112 \times 10^{3}$ & $1,0112 \times 10^{3}$ & $1,0112 \times 10^{3}$ \\
Dezembro & $2,0224 \times 10^{3}$ & $2,0224 \times 10^{3}$ & $2,0224 \times 10^{3}$ \\
\hline
\end{tabular}

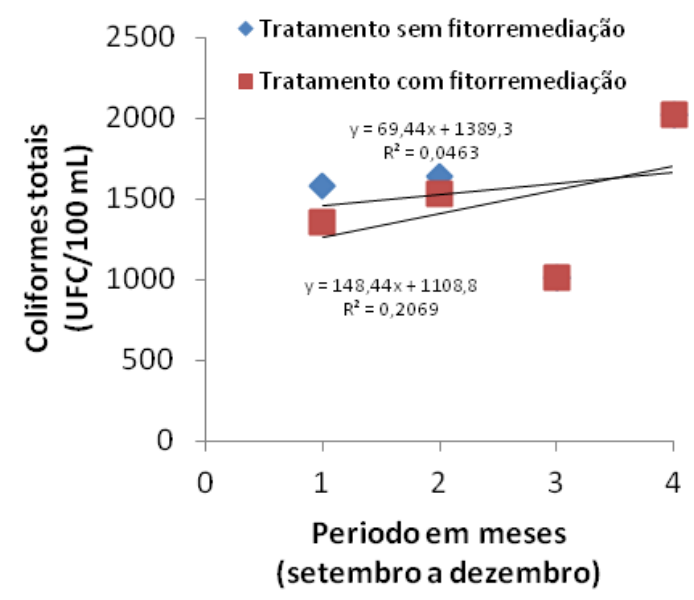

Figura 2. Gráfico de regressão linear dos tratamentos sem e com fitorremediação das águas cinza da lavanderia. 
Os coliformes totais encontrados por Borges (2003) em água cinza mistura foram de $2,4 \times 10^{3} \mathrm{UFC} / 100 \mathrm{~mL}$ e $2,4 \times 10^{5}$ $\mathrm{UFC} / 100 \mathrm{~mL}$. Rose et al. (1991) relataram concentrações de coliformes totais na água cinza variando de $10^{4}-10^{6}$ UFC/100mL. Burrows et al. (1991) relataram concentrações baixas como $85 \mathrm{UFC} / 100 \mathrm{~mL}$ na água cinza proveniente de lavanderia. Estes valores estão relacionados com a forma de uso da água na habitação, variando com as características culturais e sociais do lugar.

Na Figura 3 verifica-se a diminuição do crescimento da Escherichia coli no tratamento com fitorremediação durante os meses de monitoramento.

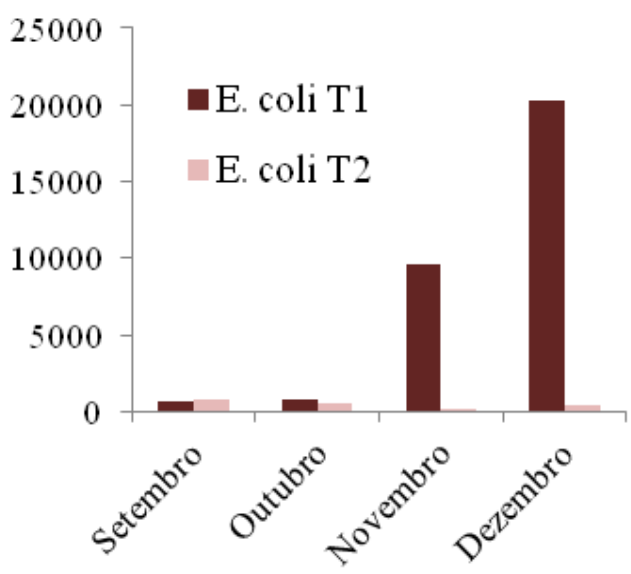

Figura 3. Presença de E.coli nos Tratamentos sem (T1) e com fitorremediação (T2).

Nos meses de setembro e outubro o capim roxo ainda estava desenvolvendo suas raízes, no entanto nos meses de novembro e dezembro percebe-se na Figura 3 uma redução visível da presença do coliforme fecal E. coli, o que não acontece com o tratamento sem a fitorremediação. A fitorremediação no tratamento de águas cinza é importante na melhora da qualidade hídrica residuária.

Na tabela 2 verificou-se a variação dos dados obtidos da presença da $E$. coli nos tratamentos sem fitorremediação e com fitorremediação. No tratamento com fitorremediação ocorre uma redução na presença da $E$. coli, tornando assim este tratamento bastante eficiente.

De acordo com a Tabela 2 no mês de novembro a redução de $E$. coli foi maior quando comparado as outras épocas, porém a maior remoção foi no mês de dezembro quando comparado com o valor do tratamento sem fitorremediação.

Tabela 2. Quantidade de E.coli nos tratamentos sem e com fitorremediação.

\begin{tabular}{lcc}
\hline E. coli & Tratamento sem fitorremediação & Tratamento com fitorremediação \\
\hline Setembro & 705 & 799 \\
Outubro & 835 & 530 \\
Novembro & 9600 & 193 \\
Dezembro & 20224 & 402 \\
\hline
\end{tabular}

Carneiro (2008) afirma que a E.coli produz catalase, utiliza glicose, amônia e nitrogênio como fontes de carbono. Esta afirmação sugere uma competição de nitrogênio, já que o capim elefante roxo depende do nitrogênio para seu desenvolvimento. Desta forma no desenvolvimento da cultura houve a redução da quantidade de E.coli prevalecendo o crescimento favorável do capim roxo.
A partir do teste $\mathrm{z}$ binomial foi possível verificar na Tabela 3 que os tanques sem capim apresentaram significativamente maior presença de E. coli do que os tanques com capim. A partir destes resultados pode-se evidenciar que o processo fitorremediativo influenciou de forma significativa na qualidade hídrica. Este é o primeiro relato do uso de capim elefante roxo, com efeito, fitorremediativo sob a $E$. coli.

Tabela 3. Comparação quanto à presença de E. coli entre a média dos tratamentos sem fitorremediação (T1) e a média dos tratamentos com fitorremediação (T2) aos 30 dias e aos 120 dias

\begin{tabular}{|c|c|c|c|}
\hline Tempo de crescimento do capim & Comparacão quanto à presença da E.coli & $\underline{z}$ & $\underline{\underline{P}}$ \\
\hline$\underline{30 \text { dias }}$ & $\underline{\mathrm{T} 1 \text { vs } \mathrm{T} 2}$ & $-81,65$ & $\leq 0.001$ \\
\hline 120 dias & $\mathrm{T} 1 \mathrm{vs} \mathrm{T} 2$ & 22,05 & $<0.001$ \\
\hline
\end{tabular}

O tratamento de águas cinza da lavanderia pública que antes eram lançadas ao meio ambiente sem nenhum tratamento contaminando o solo e a água é uma alternativa sustentável e viável promovendo o desenvolvimento sustentável da região.

Percebe-se que o tratamento anaeróbico com o auxilio do capim roxo é uma maneira de reduzir os coliformes totais e 
fecal encontrados nas águas cinza produzidas na lavanderia da comunidade. A água tratada pode ser utilizada nas UPAC's para produzir forragens para os animais como cultivar frutíferas para a população.

\section{CONCLUSÃo}

O tratamento das águas cinza com fitorremediação é eficiente reduzindo os coliformes totais e com bastante eficácia na minimização da presença dos coliformes fecal $E$. coli. Desta forma ocorreu uma qualidade hídrica.

A fitorremediação é uma alternativa sustentável e viável possibilitando a utilização de água cinza tratada através das UPAC's com o auxilio do capim roxo tratando a água, reutilizando pra o cultivo e produzindo alimento para o animal.

\section{REFERÊNCIAS BIBLIOGRÁFICAS}

AESA - Agência Executiva de Gestão das Águas do Estado da Paraíba. SIGaesa-web. Disponível em: http://geo.aesa.pb.gov.br/. Acesso em: 10 de agosto de 2013.

ANA. Agência Nacional de Águas. Conjuntura dos Recursos Hídricos no Brasil: informe 2011. Disponível em: < http://www2.ana.gov.br/Paginas/default.aspx>. Acesso em: 10 out. 2013

BORGES, L. Z. Caracterização da água cinza para promoção da sustentabilidade dos recursos hídricos. $91 \mathrm{f}$. Dissertação (mestrado em Engenharia Ambiental) Universidade Federal do Paraná, Curitiba. 2003.

BURROWS, W.D., SCHMIDT, M.O., CARNEVALE, R.M., SCHAUB, S.A. Development of health criteria and technologies for shower water recycle. Water Sci. Technol. 24 (9), 81-88. 1991.

CAMPOS. N.; STUDART. T. Gestão de Águas: Princípios e Práticas. 2.ed- Porto Alegre: ABRH. 2003.

CARNEIRO, L.C. Avaliação de Escherichia coli em manipuladores de alimentos da cidade de morrinhosGO. Vita et Sanitas, Trindade/Go, v. 2, n . 02, 2008.

DINARDI, A. L., FORMAGI, V. M., CONEGLIAN, C. M. R. FITORREMEDIAÇÃO. Curso de Tecnologia em Saneamento Ambiental. São Paulo, 2003.

FERREIRA, A. C. Unidade de produção agrícola irrigada com águas cinzas de lavanderia pública no semiárido paraibano. Tese (Doutorado em Engenharia Agrícola) Universidade Federal de Campina Grande. Campina Grande. 2013.

FIORI, S.; FERNANDES, V. M. C.; PIZZO, H. Avaliação qualitativa e quantitativa do reuso de águas cinzas em edificações. Revista Ambiente Construído, Porto Alegre, v. 6, n. 1, p. 19-30. jan./mar. 2006.

GALBIATI, A. F. Tratamento domiciliar de águas negras através de tanque de evapotranspiração. $38 \mathrm{f}$. Dissertação (Mestrado em Tecnologias Ambientais) -
Universidade Federal de Mato Grosso do Sul. Campo Grande. 2009.

GONÇALVES, R. F. et al. (Coord.). Uso Racional da Água em Edificações. Projeto PROSAB. Rio de Janeiro: ABES. 2006.

HARTMANN, PHILIPP. A cobrança pelo uso da água como instrumento econômico na política ambiental: estudo comparativo e avaliação econômica dos modelos de cobrança pelo uso da água bruta propostos e implementados no Brasil. Porto Alegre: AEBA, 2010.

MANCUSO, P. C. S.; SANTOS, H. F. (Ed.). Reuso de Água. São Paulo: Universidade de São Paulo, Faculdade de Saúde Pública, ABES. 2003.

MAY, S. \& HESPANHOL, I. Tratamento de águas cinzas claras para reuso não potável em edificações. REGA Vol. 5, nº. 2, p. 15-24, jul./dez. 2008.

PILON-SMITS, E. Phytoremediation. Annu. Rev. Plant Biol. 2005.

ROSE, J. B., SUN, G., GERBA, C. P. \& SINCLAIR, N. A. Microbial quality and persistence of of enteric pathogens in gray water from various household sources. Water Res, 25(1), 37-42. 1991.

SIEGEL, S. \& CASTELLAN, N.J. Nonparametric Statistics for the Behavioural Sciences. 2nd Edition, New York: McGraw-Hill. 1988. 